\title{
Leveraging agriculture for nutrition in South Asia and East Africa: examining the enabling environment through stakeholder perceptions
}

\author{
Stuart Gillespie $^{\mathbf{1}}$ - Mara van den Bold ${ }^{\mathbf{1}}$. Judith Hodge ${ }^{\mathbf{1}}$. \\ Anna Herforth ${ }^{2}$
}

Received: 21 January 2015 / Accepted: 17 March 2015 / Published online: 21 May 2015

(C) The Author(s) 2015. This article is published with open access at Springerlink.com

\begin{abstract}
South Asia and sub-Saharan Africa are the two regions of the world with the highest concentration of undernutrition. The majority of the nutritionally vulnerable populations in both regions is dependent in some way upon agriculture as a primary source of livelihood. The agriculture sector and wider agri-food system is considered to be central to sustained progress in reducing undernutrition - and yet not enough is known about how to unleash this potential. Recent scoping assessments have also revealed a paucity of information on wider political, institutional and policy-related challenges relating to the agriculture-nutrition nexus globally. Contextualized research into policy processes and the political economy of agriculture and nutrition is needed to better characterize "enabling environments" for agriculture to benefit nutrition, and how these environments can be shaped and sustained. This study aims to contribute to filling this gap, by drawing upon evidence from a set of case studies in South Asia (India,
\end{abstract}

Special section series Strengthening the links between nutrition and health outcomes and agricultural research.

Stuart Gillespie

s.gillespie@cgiar.org

Mara van den Bold

m.vandenbold@cgiar.org

Judith Hodge

hodgejudith1@gmail.com

Anna Herforth

anna@annaherforth.net

1 International Food Policy Research Institute (IFPRI), 2033 K Street NW, Washington, DC 20006, USA

2 Food and Agricultural Organization of the United Nations (FAO), Rome, Italy
Bangladesh and Pakistan) and eastern Africa (Ethiopia, Uganda and Kenya). In synthesizing results across countries, while recognizing important nuance and detail, we conclude by highlighting four key issues to be addressed. First, improving knowledge and perception of undernutrition and its links to agriculture, on the part of agricultural policymakers and programme managers. Second, generating system-wide incentives for decisions and actions to become more pro-nutrition. Third, developing transparent systems of accountability for nutritionrelevant action throughout the agriculture sector, through linking timely and actionable data and evidence with incentives. And fourth, cultivating and strengthening leadership and capacities at different levels, underpinned by adequate financing.

Keywords Nutrition · Agriculture · South Asia

East Africa $\cdot$ Policy $\cdot$ Capacity

\section{Introduction}

Globally, undernutrition is responsible for approximately $45 \%$ of all under-five child deaths (Black et al. 2013). In early life, it significantly heightens the risk of children dying from common infections such as diarrhea, pneumonia, malaria and measles. It can lead to reduced cognitive attainment and a heightened risk of obesity and chronic diseases, poverty, and maternal mortality and morbidity, which in turn contributes to the intergenerational nature of the problem (UNICEF 2013; Black et al. 2013).

With regard to undernutrition, South Asia and sub-Saharan Africa are the two high-burden regions of the world. The majority of the nutritionally vulnerable populations in both regions is dependent in some way upon agriculture as a 
primary source of livelihood. Given this, and the fact that household food security is a critical underlying determinant of nutritional well-being, the agriculture sector and wider agrifood system are considered to be central to sustained progress in reducing undernutrition. Yet, not enough is known about how to realize this potential.

In South Asia, approximately $39 \%$ of children under 5 years of age are stunted. While the prevalence of stunting in the region has declined by over a third since 1990 (from $61 \%$ in 1990 to $39 \%$ in 2011), three of the six countries that globally - have the highest number of stunted children are in South Asia. Stunting prevalence in India, Pakistan and Bangladesh is 48,44 , and $36 \%$ respectively, with India far exceeding other countries in terms of the number of stunted children (UNICEF 2013). In sub-Saharan Africa, progress in reducing undernutrition has also been lagging behind other regions over the last decade. Levels of stunting for children under 5 years of age in the region are $42 \%$, with Ethiopia above the average at $44 \%$ and Kenya and Uganda both below, at 35 and $33 \%$, respectively (UNICEF 2014). Despite significant progress in reducing stunting in Ethiopia (down from $51 \%$ in 2000) current rates are still very high, while wasting rates have remained high, at $10 \%$ in 2011 (Ethiopia Central Statistical Agency and ICF International 2012). Similarly, stunting rates for Kenya have stagnated with a range of 30$35 \%$ over the last decade (UNICEF 2014). Stunting in Uganda has shown a downward trend, from levels of nearly $40 \%$ in 2000 (UNICEF 2014), while wasting has remained at around four percent. In sub-Saharan Africa, child overweight rates are similar to those in Latin America (approximately $8 \%$ ), and are growing at a faster rate than other regions (Black et al. 2013; UNICEF, WHO and The World Bank 2012).

In each of the case study countries, agriculture continues to play an important role in the overall economy, employing a large percentage of the work force in each country, from 45 to $47 \%$ in Pakistan and Bangladesh (Balagamwala and Gazdar 2013; Cheong et al. 2013), to $58 \%$ in India. India, Bangladesh, and Pakistan have seen positive economic growth rates over the past several years, with agriculture making up between 17 and $25 \%$ of GDP in 2013 (World Bank 2014a). In East Africa, an even higher proportion of the population is reliant on the sector for their livelihoods than in South Asia: $75 \%$ in Ethiopia, $68 \%$ in Kenya and $72 \%$ in Uganda (FAO 2014a, b, c). In Ethiopia agriculture accounts for over $46 \%$ of GDP and nearly $40 \%$ of the rural farming population (about 5 million households) cultivates land of less than half a hectare, from which they produce only half of their annual food needs (FAO/ CAADP 2013a). In Kenya, the sector directly contributes to $24 \%$ of GDP, and $27 \%$ of GDP indirectly through linkages with manufacturing, distribution and other service related sectors (KARI 2012). Agriculture is one of the primary growth sectors in Uganda, accounting for $24 \%$ of GDP in 2011/12 (FAO/CAADP 2013b).

While agriculture has the potential to be a strong driver of reductions in undernutrition, the sector is currently not realizing this potential (Ruel and Alderman 2013; Gillespie et al. 2013; Balagamwala and Gazdar 2013; Kadiyala et al. 2014). Agriculture can deliver relatively high economic returns to investment which benefit nutrition (Hoddinott et al. 2012; Ruel and Alderman 2013), but an increase in food production or consumption does not automatically lead to improvements in final nutrition outcomes. Furthermore, agricultural GDP growth is associated with faster reductions in stunting, but also faster rises in obesity, than non-agricultural GDP (Webb and Block 2012). The food that is most easily available, affordable, and convenient is not necessarily aligned with optimal nutrition and health outcomes (Herforth and Ahmed 2015). Non-food factors such as poor sanitation, women's disempowerment, inadequate quality of health services and agriculture-associated diseases can adversely affect nutrition.

The 2013 Lancet Maternal and Child Nutrition Series demonstrated the importance not only of nutrition-specific and nutrition-sensitive interventions (such as those implemented through the agriculture sector) for achieving nutrition security, but also of an "enabling environment", defined as "policy and policy processes that build and sustain momentum for the effective implementation of actions that reduce undernutrition" (Gillespie et al. 2013). Without the necessary political will, informed by knowledge about nutrition and high quality data, facilitated by horizontal and vertical coherence (multisectoral and multilevel coordination), and supported by human and organizational capacity and sufficient financial resources, it will be difficult for sustained reductions of undernutrition to take place in any context (Gillespie et al. 2013).

This study revolves around perceptions of key stakeholders on certain issues related to agriculture and nutrition. Perceptions of the problem of undernutrition, of its causes and in particular of the interrelationships between agriculture and nutrition are pivotal in fostering enabling environments. In a comparison of stakeholder priorities and perceptions of malnutrition in Afghanistan, Levitt et al. (2009) found that agriculture and health sector stakeholders differed consistently in problem definition. Consensus-building using a shared causal framework, strategic alliances, and policy entrepreneurs with operational and strategic capacity were factors that allowed the policy process to proceed more successfully (Levitt et al. 2011).

\section{Objectives, design and methodology}

Against this background, we seek in this paper to explore some of the major political, institutional and policy- 
related challenges to cultivating an enabling environment for nutrition-sensitive agriculture in South Asia and East Africa.

The paper shares results from work conducted as part of two linked initiatives - LANSA and LANEA - in South Asia and eastern Africa respectively. LANSA (Leveraging Agriculture for Nutrition in South Asia) is an international research consortium (2012-2018) that examines how South Asian agriculture and related food policies and interventions can be designed and implemented to increase their impacts on nutrition, especially the nutritional status of children and adolescent girls. One of LANSA's three research pillars focuses on understanding, cultivating and shaping enabling environments for nutrition-sensitive agriculture; it examines how enabling this political /economic/social context is in linking agriculture and food systems to other determinants of nutritional status (e.g., women's status, sanitation), and what some of the barriers and facilitators are to nutritionsensitive agricultural development South Asia. ${ }^{1}$ As part of the research under this pillar, several review and mapping exercises were carried out between 2012 and 2014 in India, Bangladesh and Pakistan, comprised of: i) evidence reviews of pathways between agriculture and nutrition, ii) policy reviews mapping out the main agriculture/food policies and programmes, iii) stakeholder mapping and indepth interviews to gain an understanding of the current policy landscape in relation to agriculture and nutrition, and iv) national consultations with key stakeholders to share, validate, critique and extend the findings of this work.

In East Africa, a similar initiative was undertaken. Leveraging Agriculture for Nutrition in East Africa (LANEA) is a collaboration between the International Food Policy Research Institute (IFPRI) and the Food and Agriculture Organization of the United Nations (FAO) in Ethiopia, Kenya and Uganda. LANEA followed the same objectives and process as LANSA in 2013-14. This paper highlights the key findings from the interviews and the national consultations undertaken in 2013 and 2014 in these six countries.

The structure of the LANSA and LANEA stakeholder interviews was adapted from the framework used in the fourth paper of the Lancet series (Gillespie et al. 2013), which identified three core domains as key to generating change: a) evidence, framing and narratives, b) politics and governance, and c) capacity and resources. We thus

\footnotetext{
${ }^{1}$ The other two research pillars focus on how agricultural growth strategies and public-private engagement can improve nutrition, and how agricultural interventions can be designed to improve diet quality and improve nutrition.
}

set out in this study to explore stakeholder perceptions of nutrition and its links to agriculture; perceptions on what kind of evidence is available, needed, and influential on policy-making; political, institutional and governance challenges and opportunities for enhancing the nutrition sensitivity of agriculture, including incentives and disincentives; and finally key issues with regard to capacity and financing.

In both regions, stakeholders belonging to, or associated with, the agricultural sector were primarily targeted, as they hold considerable power in government planning; stakeholders from health and other sectors were also included. Furthermore, LANSA focal points in each country sought a balance between decision-makers/influencers in agriculture and nutrition policy, value chains/private sector, and advocacy and knowledge brokers. In South Asia, stakeholders were identified during mapping exercises in each country in the region in 2012, supplemented by evidence reviews and informal conversations with experts on agriculture, nutrition or health. This resulted in a 'long list' of stakeholders for each country. These 'long lists' were shared with LANSA research leads and further reduced to 'short lists' that would be manageable and realistic for interviewers to complete within 2 to 3 months. Study participants were chosen through purposive sampling to explicitly select stakeholders who were likely to generate useful, appropriate and in-depth data. ${ }^{2}$ The final numbers of interviewees was subject to interviewee availability. Between 13 and 22 interviews were ultimately conducted per country, with interviewees representing government, research, civil society, bi- and multi-lateral organizations, the media, and the private sector (Table 1).

Most of the interviews were recorded and then transcribed. When not recorded, interview notes were written up by the interviewer. Interviewers conducted the interviews with the support of a guide, which consisted of open-ended questions on the three themes. Information from both interview transcripts and notes was subsequently categorized in an Excel matrix according to codes that represented the three major domains, as well as sub-codes to capture more detailed information. Quotes and reflections from the interviewee were also captured in this matrix. Data analysis and write up were based on the information captured in the matrix.

\footnotetext{
${ }^{2}$ Stakeholders were categorized according to: their role, their institution, the institution type, the individual's influence in the agriculture-nutrition policy space (high, medium, or low), their level of influence (e.g., provincial, state, national), their support for improving agriculture for nutrition, the sector (s) they belonged to, the reasons why they were targeted by LANSA as a potential interviewee, and whether or not they had been interviewed by any of the organizations in the LANSA consortium recently.
} 
Table 1 Number, background, and gender of interviewees in study countries

\begin{tabular}{|c|c|c|c|c|c|c|c|}
\hline & \multicolumn{3}{|l|}{ South Asia } & \multicolumn{3}{|l|}{ East Africa } & \multirow[t]{2}{*}{ Total } \\
\hline & Bangladesh & India & Pakistan & Ethiopia & Kenya & Uganda & \\
\hline Ministry of Agriculture & $1(\mathrm{~m})$ & & $2(1 \mathrm{f} / 1 \mathrm{~m})$ & $6(1 \mathrm{f} / 5 \mathrm{~m})$ & $4(3 \mathrm{f} / 1 \mathrm{~m})$ & $2(1 \mathrm{f} / 1 \mathrm{~m})$ & 15 \\
\hline Other ministries / departments & $4(4 \mathrm{~m})$ & $4(2 \mathrm{f} / 2 \mathrm{~m})$ & $7(1 \mathrm{f} / 6 \mathrm{~m})$ & $1(\mathrm{~m})$ & $1(\mathrm{~m})$ & $6(2 \mathrm{f} / 4 \mathrm{~m})$ & 23 \\
\hline Civil society/NGOs & $4(1 \mathrm{f} / 3 \mathrm{~m})$ & $7(2 \mathrm{f} / 5 \mathrm{~m})$ & $3(3 \mathrm{~m})$ & $4(4 \mathrm{~m})$ & $1(\mathrm{f})$ & $5(3 \mathrm{f} / 2 \mathrm{~m})$ & 24 \\
\hline International agencies & 1 (f) & $2(2 \mathrm{~m})$ & $3(3 \mathrm{~m})$ & $3(1 \mathrm{~m} / 2 \mathrm{f})$ & $4(3 \mathrm{f} / 1 \mathrm{~m})$ & $2(1 \mathrm{f} / 1 \mathrm{~m})$ & 15 \\
\hline $\mathrm{Bi}-/$ multi-lateral donors & $1(\mathrm{~m})$ & & $1(1 \mathrm{f})$ & $4(2 \mathrm{~m} / 2 \mathrm{f})$ & & $1(\mathrm{~m})$ & 7 \\
\hline Research & $1(\mathrm{~m})$ & $4(3 \mathrm{f} / 1 \mathrm{~m})$ & $2(2 \mathrm{~m})$ & & $2(1 \mathrm{f} / 1 \mathrm{~m})$ & $2(2 \mathrm{~m})$ & 11 \\
\hline Industry / private sector & & $2(1 \mathrm{f} / 1 \mathrm{~m})$ & & $1(\mathrm{~m})$ & $3(1 \mathrm{f} / 2 \mathrm{~m})$ & $1(\mathrm{f})$ & 7 \\
\hline Media & $1(\mathrm{~m})$ & $1(\mathrm{~m})$ & & & & & 2 \\
\hline Other & & $2(2 \mathrm{~m})$ & $3(3 \mathrm{~m})$ & & & & 5 \\
\hline Total & $13(2 \mathrm{f} / 11 \mathrm{~m})$ & $22(8 \mathrm{f} / 14 \mathrm{~m})$ & $21(3 \mathrm{f} / 18 \mathrm{~m})$ & $19(5 \mathrm{f} / 14 \mathrm{~m})$ & $15(9 \mathrm{f} / 6 \mathrm{~m})$ & $19(8 \mathrm{f} / 11 \mathrm{~m})$ & $\begin{array}{l}109 \\
\quad(35\end{array}$ \\
\hline
\end{tabular}

\section{Results}

\section{Evidence, framing, narratives: stakeholder perceptions of nutrition and agriculture}

Overall, we found that the notion of nutrition itself differed significantly among stakeholders. Some considered "nutrition outcomes" to refer to child growth or micronutrient status, while others perceived improved food access and diets to be primary nutrition outcomes. For many stakeholders, stunting and child nutrition are primarily health issues, under the purview of the Ministry of Health, not directly affected by agriculture. As one interviewee stated: "Nutrition is perceived to be a concept outside agriculture and its [agriculture's] indicators can't check for reductions in stunting, rather they will check on number of households without food or with food diversification" (Ministry of Agriculture (MoA) official, Ethiopia).

In all countries, we found a common perception that as agriculture provides food and income, it is not only relevant for nutrition, but potentially sufficient for good nutrition. In the three South Asian countries, nearly two-thirds of interviewees perceived agriculture as mainly affecting nutrition through the production (and hence increased availability) of food. Agriculture was also identified as a key source of income for producers and agricultural workers. The impact of agricultural policies on prices was highlighted, both for farmers' income as well as for improving consumer purchasing power and potentially food consumption. Only 1 in 5 South Asian respondents mentioned other pathways through which agriculture can impact nutrition, such as through women's empowerment and/or control over resources. In India, the persistence of high malnutrition rates - despite economic growth and investments in the agricultural sector, and the country's achievements in agricultural production - is finally allowing more space for nutrition in policy discussions. One interviewee stated that the "[production] challenge has been overcome, so I believe there is a great window of opportunity to talk about other things than production, and nutrition is obviously the one that comes next" (International Organization representative, India). In Bangladesh, despite the tendency (as reported by several respondents) to focus primarily on rice and wheat production, the government and several other organizations are starting to recognize the importance of diversifying diets and making agriculture more nutrition-sensitive, although this agenda still seems to be driven by development partners. A smaller number of interviewees emphasized that nutrition is gaining prominence, exemplified by Pakistan joining the Scaling Up Nutrition (SUN) movement, provincial initiatives for developing multisectoral nutrition strategies, an increasing number of nutrition-sensitive agricultural programmes, and improvements in biofortification (iron and zinc-fortified wheat varieties).

In East African countries, the pathways from agricultural production to nutrition through income generation, household food production, education, and (to a lesser extent) through women's empowerment were identified by respondents. Often stakeholders would refer to just one of these pathways. Others appreciated the complexity and synergies between pathways (this was particularly evident in Ethiopia where over two thirds of respondents mentioned two or more pathways). The most common way that African stakeholders suggested agriculture could become more nutrition sensitive was through agricultural diversification and focusing on consumption of foods of high nutritional value such as African leafy vegetables, small animals like poultry, fish, dairy products and eggs. Biofortified crops such as iron-rich beans and orangefleshed sweet potatoes were discussed in all three countries, with respondents highlighting government's 
potential role in promoting them. Post-production, strategies include minimizing wasteful food processing that removes nutritional value, for example in maize, and storing and preserving food hygienically. Stakeholders in all three African countries also mentioned education to ensure appropriate diets.

Women's empowerment in agriculture was discussed in most countries, though to a much lesser extent than food production: "Empowering and targeting women will have an effect on the nutritional status of children. When women control the resources, they are more likely to use it for family consumption and that will improve the nutritional outcomes (Ministry of Health (MoH) official, Ethiopia). Apart from income, empowerment was discussed in terms of promoting adoption of labor saving technologies and more equitable labor sharing. The notion that agriculture as a major employer of poor rural women (many of whom are mothers of young children) generates other non-food pathways to nutrition is not commonly understood among, or highlighted by, stakeholders in both regions. One interviewee in Pakistan suggested that most aspects of the food system are controlled by men, which is why nutrition does not receive priority (Men understand money; women understand nutrition"), and that agricultural extension systems are heavily dominated by men, compromising important interactions with women around agriculture and nutrition.

Many respondents discussed income generation being seen as a bona fide pathway to improved nutrition. At the same time, market orientation was often discussed as almost an either/or choice with increasing production of nutrient-rich foods. Agricultural policies were thought to prioritize market access, value addition and the commercialization of agriculture. From Uganda: "Household nutrition is neglected ... [It is only] what is left after the market that is available for household food consumption" (Office of the Prime Minister representative) and "Nutrition sensitivity could be improved by promoting production of nutritious foods over and above the cash generating foods" (Office of the Prime Minister representative). There were few comments focusing on win-win scenarios, making nutritious food more profitable, or increasing markets for nutritious food, with the majority coming from the private sector.

When asked about potential negative effects of agriculture, nearly $50 \%$ of respondents in all three African countries tended to focus on the balance between export and local consumption affecting local availability and prices of food ("we produce oil seeds mainly for export and the local consumption is being neglected" (donor organization representative, Ethiopia). The land allocated to cash crops was also noted as affecting availability of land for food. For example "if more coffee is produced at the expense of certain cereals, you are increasing the price of cereals in the market and the same is true for Khat" "(donor representative, Ethiopia). In Ethiopia, there was concern about women engaging extensively in physical labour as negatively affecting children's nutrition - and about the potential negative impact of irrigation via increasing water-borne illnesses. Other environmental impacts on nutrition such as nutrient-deficient soils and climate change were also mentioned (e.g., "the agriculture sector in Ethiopia is the one that takes the lion's share of the greenhouse gases resulting from natural resource degradation and from the methane gas being produced by the livestock population. This might negatively affect nutrition because of the resulting effect on the environment" (MoA official, Ethiopia).

\section{Perceptions of evidence on agriculture-nutrition linkages}

Perceptions of the kind of "evidence" available and needed fell into two types: experimental research evidence, and basic data showing evidence of problems. On the research side, some responses pointed to a desire to identify a universal single mechanism on how agriculture affects nutrition, and to be able to predict percentage point reductions in stunting from certain actions. This viewpoint, emphasized by healthsector respondents in eastern Africa, is informed by direct interventions that have a predictable, universal biological effect. There was a desire to disentangle and identify the effects of food production/diversification, income generation, and women's empowerment: "We don't know exactly which one affects. Is it the income, the diversity, the women empowerment or the value chain that affects nutritional outcomes? We don't have much evidence" (NGO representative, Ethiopia). On the other hand, many stakeholders recognized context dependence, for example calling for production choices based on nutritional deficiencies in a given area. In Ethiopia and Uganda, respondents commented that the evidence should be specific to the livelihood under discussion, "because there are more than 250 different livelihoods in the country" (Donor representative, Ethiopia). In Uganda, respondents were particularly vocal about community participation and dialogue to come up with solutions to nutrition problems, and about being sensitive to cultural values and traditions.

Respondents in Uganda and Kenya felt that it would be useful to improve specific kinds of evidence, such as that on diet diversity in households, communities and regions; women's empowerment in agriculture; how household income influences nutrition; and the strength of community development work in community mobilization. In South Asia, more research was also cited as being needed on value chains

\footnotetext{
${ }^{3}$ Khat, a leafy plant used as a mild stimulant in the Horn of Africa, is an important cash crop for many farming households.
} 
(preserving, storing, transporting) and nutrition, micronutrient-rich crops as opposed to staples, and on scaling up of nutrition-sensitive pilot projects.

Respondents felt that evidence tends to be more useful if it is practical and actionable - showing "how" agriculture can become more nutrition-sensitive in real world field conditions, at scale - and if it is written and communicated in the "language" of policymakers. More operational evidence is seen to be needed by many stakeholders in all countries. An international organization representative in Ethiopia explained that "projects need to have flexibility to generate more evidence through operational research with regards to the impact of agriculture on nutrition outcomes, not just implement $i t$ ". Stakeholders in Uganda explained that project activities can be leveraged for generating best practices/lesson learned, capacity-building and the development of Information, Education and Communication (IEC) materials. And in Bangladesh, stakeholders emphasized that research has an opportunity to influence policy but it needs to be robust and implementable.

\section{Availability of data}

Although not often viewed as "evidence" by the research community, many respondents talked about evidence in terms of improving basic data to shed light on the status and trends in nutrition. Several respondents in Ethiopia and Uganda also suggested that simply revealing and communicating the status quo more clearly could shake assumptions and inspire interest: "the evidence that some regions can have increased food production and yet remain malnourished is big evidence that malnutrition has not been tackled through increased food production alone" (Ministry of Gender, Labor and Social Development official, Uganda).

In South Asia, opinions on availability of useful and actionable data differed in each country. Many respondents felt there was insufficient data firstly on nutrition (e.g., in India the National Family Health Survey, which will be conducted in 2014, has not been carried out since 2005-6, and in Pakistan, the National Nutrition Survey is undertaken only every ten years) and secondly, on agriculture (e.g., agricultural statistics data were perceived by one respondent as being outdated and unreliable). Third, evidence on agriculture-nutrition linkages was also perceived to be scarce and mainly from small-scale pilot projects.

Others felt that the main issue was poor use of existing data: "There is a need to triangulate data from the Development Agents and Health Extension Workers with nutrition indicators. The Community-based Nutrition (CBN) programme and the Productive Safety Net Programme (PSNP) also bring lots of information every year and so are the food security programmes. The evidence might be there but analysis and interpretation needs to be improved" (MoH official, Ethiopia).
Generally, African respondents felt that existing data were insufficient for enabling policy decisions and appropriate action. There is a perceived lack of data to facilitate understanding of the causes of malnutrition, resulting in an inability to choose policy options that might alleviate it: "Ethiopian Demographic and Health Survey $(E D H S)$ is a fact sheet that indicates a surplus producing region in Ethiopia, the Amhara region, is having the highest level of stunting in the country. How it happened and what makes those differences whether it is due to health interventions, agricultural interventions or which one....we don't know" (International Organization representative, Ethiopia). "Data is available-largely UDHS data, but it comes once every 4 years, and its focus is on the health side of nutrition" (Research institute representative, Uganda). Another respondent in Ethiopia (from an international organization) noted that "we don't know what we actually eat". Several respondents talked about limitations in available data - that it was inaccurate and late, and/or "does not disaggregate sufficiently to regional or district level. Research also needs to be contextualized to a district local environment(International Organization representative, Uganda).

\section{Policy, politics and governance}

In this section, we focus on perceptions of the role of policy, political power and governance systems and processes. In particular, the extent to which these forces provide an enabling environment for maximizing the contribution of agriculture to nutrition. There are many important factors to consider here, but we focus in particular on issues of political priority, policy coherence (across and within sectors), ownership, coordination, implementation and accountability.

\section{Policy and priority}

In any one country, certain policies set the stage for strengthening nutrition and agriculture linkages. To influence government policy in Ethiopia, for example, there's a need to influence the Growth and Transformation Plan (GTP) because it provides the overall strategic framework and all other sectoral policies, including agriculture, need to align with it. Similarly, Kenya's Vision 2030 is a development blueprint for the country's projected economic growth, and nutrition is implied (though not expressly mentioned) in all major government policies targeting the agriculture sector. However, these policies are not always sufficient, either in scope or implementation, to create change on the ground. The extent to which policies themselves or their implementation enable agriculture to improve nutrition is affected by political priority given to the issue, ownership within and across sectors and levels of governance, and accountability.

Links between policies and programmes are two-way. Again, in Ethiopia, flagship programmes like Productive Safety Net Programme (PSNP) and the Agricultural Growth 
Programme (AGP) generate findings which can help inform future policies. Programmes are not simply downstream manifestations of policy intent.

Policies are seen to be driven by vote-winning issues, and nutrition is rarely viewed as a vote-winner. In Uganda, "decisions are politically driven and influenced by the level of political support that can be gained" (Office of the Prime Minister official, Uganda). Malnutrition is often "invisible" including to those who suffer from it, and this - along with its complex, multifaceted nature - renders it difficult for a strong bottom-up demand for action to be generated. These perceptions were also pervasive in Pakistan and India. Individual leadership (within or outside government) is seen as an important driver of policy decisions in all three South Asian countries. In addition to individual "champions", networks and alliances can have major influence e.g., the Coalition for Sustainable Nutrition Security in India.

The political priority that governs agriculture's contribution to nutrition is largely limited to staple grain production and income generation. Over half of interviewees in India (12/22) - from research, civil society, industry, government, and the media - asserted that the prevailing emphasis on staples such as wheat and rice (including in programmes like the Public Distribution System) has shifted policy (including price policy) and programmatic focus away from pulses, vegetables, fruits, and micronutrients, as well as indigenous/traditional farming systems. In Pakistan, the focus is on staple food self-sufficiency, not nutrition per se. Seven out of the 21 interviewees in Pakistan found that nutrition is not a priority in the agricultural sector. One official from a provincial Planning and Development department in Pakistan explained: "Our focus is on [...] self-sufficiency. We might get into enhancing nutritional value once we have addressed these issues. [Once] food security $[i s]$ ensured [and] we have exportable surplus, then this [nutrition] might be the priority" (Planning and Development Department official, Pakistan). Interestingly, this quote reveals a conception of even food security - a common goal of the agriculture sector - as national-level grain self-sufficiency, which is at odds with the globally-accepted definition as access to nutritious diets (FAO 1996).

\section{Other drivers of change}

In all three African countries, in particular, the importance of the Scaling Up Nutrition (SUN) movement was mentioned (SUN is a collective effort among governments, civil society, the United Nations, the private sector and researchers to improve nutrition). In Kenya, SUN membership helped with launching the Nutrition Interagency Coordinating Committee (NICC) with 10 key line ministries, including ministries of environment, water, agriculture, trade and health. In Uganda, international momentum, driven in part by the SUN movement, led to the prime minister making commitments at a global level to reduce malnutrition. The African Union (AU) and the Comprehensive Africa Agriculture Development Programme (CAADP) investment plan process (an AU-led initiative to address policy and capacity issues across the entire African continent) are also key influencers, as are donors (especially in African countries and Bangladesh)

There are other important events or influences described by stakeholders. In India, for example, two of the main catalysts mentioned were the debate leading up to the development of India's Food Security Bill, and IFPRI's "Leveraging Agriculture for Improving Nutrition and Health" 2011 conference in New Delhi.

\section{To what extent does evidence influence policy?}

How important is evidence in shaping policy and practice? In eastern Africa, respondents from Ethiopia and Uganda differed sharply in their views on this. In Ethiopia, it was felt that there is an appetite and a mandate for evidence-informed policy-making. "Evidence is more crucial in the Ethiopian society unlike some countries, like Brazil, where getting the buy in from the masses is sufficient to influence policy" (donor agency representative, Ethiopia). In contrast, in Uganda one respondent said that "there is no incentive to use research; it all depends on individual interest and attitude. Often we quote the same data over and over until we are challenged and provided with new data" (Uganda). In both India and Pakistan, respondents mentioned that research/ evidence can and does inform policy making but that often policy makers do not have time to wait for or examine evidence in detail. A lack of accountability (discussed later) was also seen as a disincentive to evidence-informed policymaking.

The importance of highlighting the economic benefits of addressing undernutrition (and/or the economic losses due to inaction) was emphasized by some. ${ }^{4}$ Incentives and accountability are of course critical for generating interest and action. One NGO representative in Ethiopia stated that "We need to come up with evidence that shows the economic impact and return, and the productivity impact and return". Another stated that evidence should clearly show policy makers what they are going to gain by investing in nutrition-sensitive agriculture, and to ensure that it is included in the performance contract of higher officials as an incentive. Another stated that "The mainstreaming of nutrition has to fit within the vision of the sector and be embedded within their system, like on the promotion of perennial crops and fruit trees...we should not expect them to do what the MoH does for it is not their area of interest" (NGO representative, Ethiopia).

Several stakeholders however found that policy is in fact not strongly informed by evidence. Policies are often perceived to be driven by emotional arguments, and policy

\footnotetext{
${ }^{4}$ In Ethiopia, reports such as "The Cost of Hunger", which indicated the social and economic effects of child under-nutrition in terms of education and productivity, and showed that nutrition is not only a health issue, help influence policy formulation. The study has been presented to the cabinet by the Minister of Health.
} 
makers are considered not to have time to wait for evidence, and to be under constant pressure from interest groups. Agricultural policies in South Asia have remained entrenched, with reforms continually resisted by powerful lobbies such as growers' associations, fertilizer associations and private sector actors. In India, several respondents felt that policymakers prioritized issues for which (early) impacts were more likely to be measurable and attributable to their decisions. Nutrition was seen as too complex and too long-term. An interviewee in Bangladesh explained that as the policy formulation process is so participatory, it can take a very long time to complete. This may delay action, but extensive consultation was viewed as enabling wider ownership and supporting a more evidenceinformed policy.

\section{Horizontal coherence: ownership and coordination of nutrition-sensitive agriculture}

Overall, stakeholders perceived widespread attention to the multisectoral nature of the nutrition challenge, at least in terms of speeches and policy statements. In East Africa (and to a lesser extent in South Asia), food and nutrition security is routinely mentioned within agriculture policies, and the agriculture sector is often viewed as a lead sector in multisectoral action plans.

There is some question as to whether multisectoral collaboration is as important as clear goals and actions (supported by adequate capacity and financing) within each sector. Some respondents viewed it as critical that each sector has goals for nutrition that are aligned with the sector's mandate and priorities. An interviewee in Uganda stated that: "Nutrition indicators could be used in performance assessment of local government agencies using relatively simple measures of nutrition. Local governments and others could incorporate such measures as basic anthropometry and household dietary diversity into their monitoring and evaluation systems" (International organization representative).

Institutional arrangements are key for coordination and ownership. Nutrition often sits within the Ministry of Health, or within Home Economics units of the Ministry of Agriculture and the responsibility to coordinate is rarely backed with the authority, power and resources to do so. In the case of Uganda, nutrition is housed in the Office of the Prime Minister but lacks its own budget. While the Ministry of Women and Child Development (MWCD) in India has the official mandate to convene different departments on nutrition, it is not perceived to have the status and the power to do so effectively. Where nutrition is considered within agriculture, in most cases it tends to be "projectized", not mainstreamed. This tendency reflects a core lack of ownership of the nutrition issue within the agriculture sector. From an Ethiopian interviewee: "These individuals [responsible for nutrition] representing the different ministries in the inter- sectoral meetings need to have an incentive i.e., for their work to be recognized and measured into their performance monitoring, but this is not the case at the moment. There is a need to include nutrition in the annual work plan of the MoA at different levels i.e., from Federal all the way down to the Kebele level" (Ethiopia).

Relationships between ministries and agencies in both regions were characterized by a number of interviewees as "competitive rather than coordinated" particularly when competing for funding, and there were weaknesses of inter- and intra-coordination in districts and government sectors. "The current administrative structure encourages silo programming and competition - [there is] no motivation for collaboration" ( $N G O$ representative, Uganda).

Five of the six countries have, in recent years, developed multisectoral/multistakeholder platforms (as part of the SUN movement) while India has made recent advances on multisectoral approaches. Multistakeholder platforms that do exist, however, are not perceived to be strong, as stakeholders are busy meeting targets of their own sectoral programmes and there is limited emphasis on seeking and exploiting synergies on cross cutting issues. Coordination capacity (discussed in the capacity section below) is limited.

\section{Vertical coherence: implementation and accountability}

Even if policy is in place, and there is some degree of higherlevel, cross-sectoral coordination and ownership, implementation on the ground is seen as a major challenge. To be implementable, policies need to be underpinned by appropriate governance structures, institutional arrangements, an enabling legal framework, solidly designed programme/s and clear systems of accountability and funding.

The lack of engagement of implementation partners in policy formulation, especially in decentralized systems of governance, is widely viewed as a recipe for implementation failure. Kenyan stakeholders, for example, were in general agreement that significant delays in developing the Food and Nutrition Security Policy (FNSP) implementation strategy was due to Kenya's current transition to devolved government (Devolved Government Act 2012) and the creation of a decentralized system of county governments. Counties now need to align their strategies to the national food policy and yet..."vertical coordination is being hampered as county governments seek autonomy from the central government" (LANEA workshop, Nairobi, 26 May 2014). In Pakistan, stakeholders found that since decentralization, there are limited accountability frameworks in place at provincial level and limited political will with regard to nutrition. In Bangladesh, while collaboration between sectors is improving, especially at the policy level, implementation of coordination is still largely absent.

One respondent in Ethiopia mentioned a desire to see implementation of identified pathways and principles: "IFPRI 
and other people have already defined the pathways and I completely agree to those pathways and the 10 principles have been identified by FAO..... but I want to see the implementation of those....Let's try to do that and see what happens" (International Organization representative, Ethiopia). The Ethiopia National Nutrition Policy was seen to need translation into doable activities, and "the MoA needs to be well versed with the 'how' part of nutrition sensitive programming, from policy level to the DAs [Development Agents or Agriculture Extension workers] to make sure that smallholder farmers have the right information in terms of diversifying the outputs and diversified consumption. This includes development of an action plan and translating it to doable activities" (international agency representative, Ethiopia).

Scale is another key issue. In Kenya, stakeholders highlighted various government-led agricultural initiatives/ efforts in the country that were focused on influencing nutrition outcomes. These included the promotion of production and utilization of nutritious crops such as orange-fleshed sweet potato and African Leafy Vegetables, and the nutrition component of Nja Marufuku Kenya (NMK) (Eliminate Hunger in Kenya) where school feeding has been integrated with farmers growing foods and selling to schools for income generation. There are also several food and nutrition security programmes being implemented by NGOs and donors, but it appears that most projects are operating at small scale, often on single crops, kitchen gardens and women's groups.

While a growing number of guidelines for strengthening multisectoral implementation for nutrition are being developed in consultation with development partners (especially through the SUN movement), accountability structures and processes for the most part, remain weak in most countries. Lack of accountability for specific goals or targets was cited often as an issue, which in turn relates to weak systems of monitoring and evaluation and/or weak incorporation of nutrition-relevant indices in existing systems. "For each and every nutrition sensitive intervention planned within different ministries, we need to have relevant indicators that could be linked within an overall stunting indicator" (EU representative). These indicators, however, are absent in both goals and in basic datasets (as described in the section on perceptions of evidence). Stakeholders also pointed to the need to use existing government documents to push for better accountability. For example, in Ethiopia, the Growth and Transformation Plan aims to reduce stunting to $36 \%$ by 2015 "We used it to influence the MoA because it says this will be achieved by implementing the NNP [national nutrition policy]. For agriculture people, NNP is health and therefore we are unpacking how to do it through capacity building" ( $N G O$ representative, Ethiopia). Lastly, the influence and pressure from the media and civil society seems to have positively influenced accountability mechanisms in India and
Bangladesh. The Right to Food Campaign in India was mentioned as an example of successful influencing by civil society.

\section{Capacity and financing}

One of the main objectives of the interviews was to examine perceptions about the types of capacities (individual, community, organizational, systemic) required for the agri-food sector to become more nutrition-sensitive. In all three countries in South Asia, interviewees perceived there to be a general lack of understanding about nutrition and agriculture-nutrition linkages among individual stakeholders from village to state level (community level workers, farmers, NGO workers, and civil servants) - as discussed earlier in this paper. Capacity of researchers was also said to be deteriorating in some countries due to a "brain drain" (e.g., National Agricultural Research System (NARS) in Bangladesh, and under-qualified personnel often being employed). Stakeholders also felt that policymakers' ability to actually understand and use evidence needs to be improved. In East Africa, insufficient human resource capacity was considered a significant constraint to improving nutrition-sensitive agriculture, particularly in relation to agricultural extension.

At the community level it was considered important that farmer training programmes incorporate nutrition issues instead of solely focusing on production. Donors such as USAID in Kenya offer ways to build such technical capacity, such as the Training of Trainers, which uses an agriculturenutrition manual ${ }^{5}$ - developed by the Ministry of Agriculture and the Ministry of Public Health and Sanitation - to train health workers in several counties in Kenya to communicate messages to communities and households. Respondents in Uganda as well as Ethiopia pointed out that tools for nutrition need to be developed and adapted for agriculture-nutrition behaviour change communication, and in Uganda, community development officers, religious and cultural leaders, and elders need to be more actively involved in nutrition advocacy at the community level.

At an organizational level, interviewees gave examples of some of the national institutions (of all types) that needed strengthened capacity - and the nature of this required capacity - to support nutrition-sensitive agriculture. Strategic, technical and operational capacities were perceived to be limited. Several respondents in East Africa also indicated limited capacity to undertake research on the multi-dimensional causes of nutrition and on nutrition-sensitive agriculture, which could be important for informing policy decisions, strategic planning, and nutrition-sensitive programme design. Stakeholders in both regions felt that universities need to improve the nutrition-sensitivity of their agriculture curricula. As

\footnotetext{
${ }^{5}$ Applied Basic Agr-Nutrition Resource Manual for Trainers
} 
one interviewee explained: "The capacity is limited because it [nutrition-sensitive agriculture] is not being taught [...] The knowledge needs to diffuse from the nutrition people to agriculture" (quasi-governmental agency, Ethiopia). Another big issue is rotating capacity - for example, in India, bureaucrats rotate frequently between ministries, which means little continuity in terms of policy and programming.

At a more systemic or structural level, one of the main challenges identified in both regions was weak interministerial coordination due to insufficient nutrition-relevant capacity within the government. Several other areas were identified as needing capacity strengthening, such as the extension worker system, nutrition-sensitivity of value chains, availability and affordability of technology, infrastructure, and knowledge management. In East Africa, the development of, and collection of data on, nutrition indicators, and monitoring and evaluation for nutrition were identified as areas that need improvement. Respondents in Uganda pointed to the need for stronger institutional structures at national and district levels with a supportive legal and policy framework. In Ethiopia, lack of capacity was particularly noted at federal level, but was considered stronger at regional and woreda levels. Several respondents in both regions, however, stated that political will was more important than
Table 2 Perceptions on key factors preventing nutrition from being prioritized in agriculture

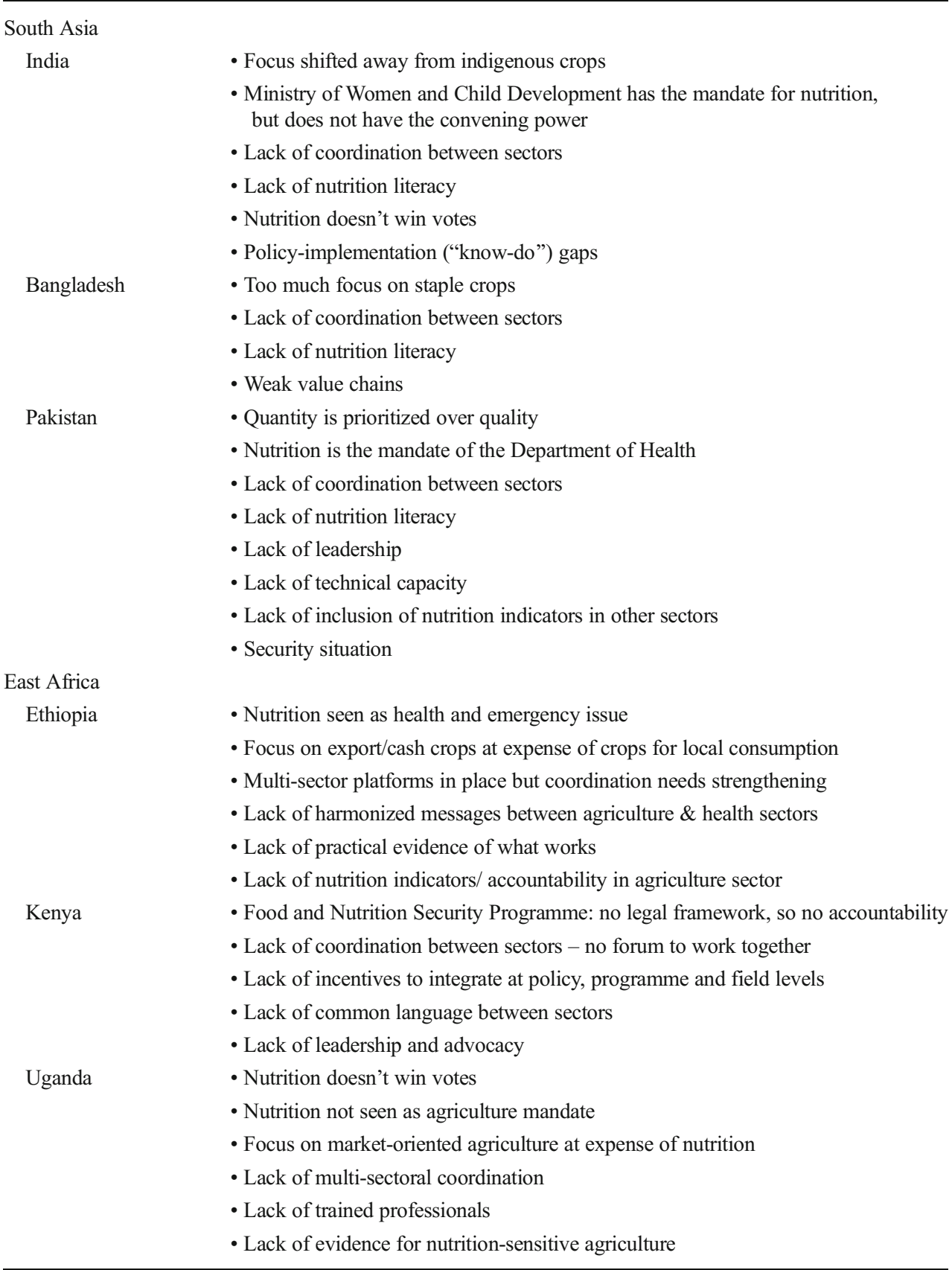


capacity gaps with regard to enhancing the nutrition sensitivity of agriculture.

\section{Sufficiency of financial resources to improve nutrition-sensitivity of agriculture}

In India and Pakistan, interviewees were split on whether there are sufficient financial resources for the agriculture/agri-food sector to improve nutrition. A substantial number of respondents felt that financial resources were not a problem, but that significant improvements were needed in terms of how resources are spent. A smaller number of respondents however felt that financial resources were not sufficient, particularly at state level and within agricultural research and development. Others mentioned that the amount of financial resources required depends on the extent of scale up, and that there is not enough evidence of cost effectiveness of programmes and of impacts of targeting to determine the extent of financial resources needed. Relatedly, several respondents were concerned about the political motivations attached to spending decisions (e.g., in Bangladesh, the Ministry of Livestock and Fisheries was seen to have limited funding compared to the Ministry of Agriculture and the Ministry of Health).

In all three countries in East Africa, respondents stated that many nutrition programmes are primarily funded by donors, usually with support from the national government. There are limited financial resources available to improve the nutritionsensitivity of the agri-food sector and there is a lack of funding for nutrition from sectors other than the Ministry of Health. Stakeholders in Kenya highlighted that the way in which funds are distributed and/or coordinated for nutritionsensitive interventions of the Food and Nutrition Security Policy (FNSP) between the Ministries of Agriculture and Health in Kenya is still problematic.

\section{Summary of findings}

Overall, broadly-speaking, our findings align with those of recent initiatives but with some important nuance and detail. In Table 2, we highlight inter-country differences in perceptions of key constraints and challenges in enhancing the nutrition-sensitivity of agriculture. And in Table 3, we summarize the main emerging issues from the case studies using the six-cell framework, adapted from Gillespie et al. (2013), cross-tabulating the core themes against two stages of response - building commitment to act, and turning such commitment into action and ultimately impact. The three themes are relevant to each stage, though the specific issues (within each cell) change as the focus shifts from left to right, or from policy statements to programme implementation.

Table 3 Summary of key issues arising from country case studies

\begin{tabular}{|c|c|c|}
\hline & Building commitment & Turning commitment into action and impact \\
\hline Evidence, data, perceptions & $\begin{array}{l}\text { Clarify agriculture-nutrition links (that go beyond food pathways) } \\
\text { Stakeholder consultations, cross-sectoral dialogue } \\
\text { Learn a new language (incentives)/nutrition literacy } \\
\text { Highlight mutual gain ("win-wins") } \\
\text { Support civil society advocacy } \\
\text { Engage the media } \\
\text { Raise awareness about nutrition at all levels }\end{array}$ & $\begin{array}{l}\text { Ensure policy is implementable } \\
\text { Generate and use actionable evidence } \\
\text { Operational research and evaluations } \\
\text { Highlight what works in programmes } \\
\text { Embed nutrition-relevant indicators in agricultural } \\
\text { Monitoring and Evaluation (M\&E) systems } \\
\text { NGO role in piloting and innovation } \\
\text { Learn about scale up and integration }\end{array}$ \\
\hline Policy, politics, governance & $\begin{array}{l}\text { Horizontal (cross-sectoral) coherence } \\
\text { Priority-setting and policy formulation processes } \\
\text { Address production bias } \\
\text { Identify mechanisms for communication and coordination } \\
\text { Decision-making incentives (for change) } \\
\text { Leadership/champions } \\
\text { Pro-nutrition legislation } \\
\text { Global and regional conferences and movements }\end{array}$ & $\begin{array}{l}\text { Vertical coherence (national to community) } \\
\text { Ensure incentives for implementation } \\
\text { Clarify and ensure accountability at all levels } \\
\text { Decide whether to integrate or co-locate programmes } \\
\text { and interventions } \\
\text { Empower women through agriculture } \\
\text { Engage private sector and other development partners, } \\
\text { based on comparative advantage. } \\
\text { Forums for sharing lessons on what works }\end{array}$ \\
\hline Capacity and finance & $\begin{array}{l}\text { Lateral leadership (across sectors) } \\
\text { Policymaker rotation problematic } \\
\text { Coordination capacity (e.g., multistakeholder platforms) } \\
\text { Capacity to demand and use research evidence }\end{array}$ & $\begin{array}{l}\text { Operational capacity / implementation coordination } \\
\text { Pre and in-service training } \\
\text { Better use of existing research capacity } \\
\text { Leveraging private sector capacity } \\
\text { Funding: not necessarily the major problem } \\
\text { North-south and South-South knowledge exchange }\end{array}$ \\
\hline
\end{tabular}




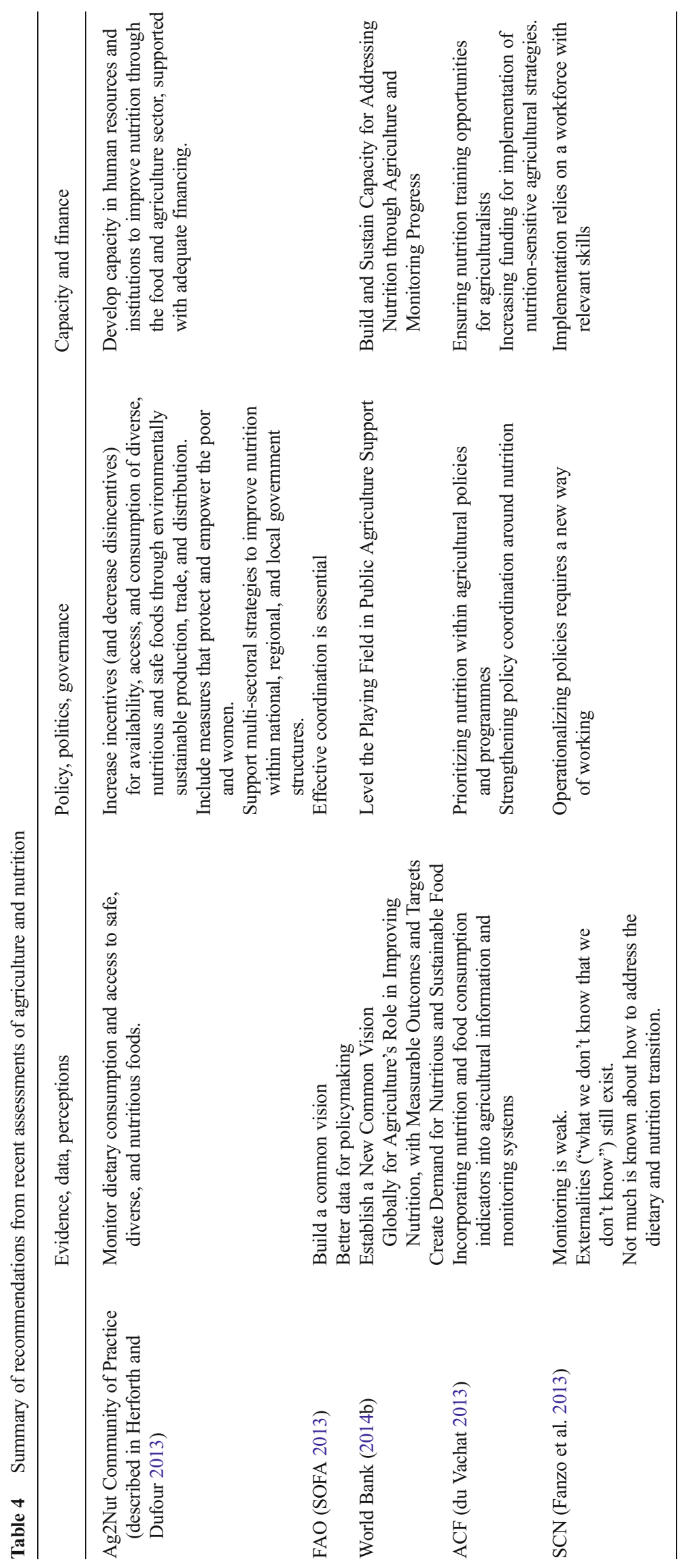




\section{Discussion}

It is important to emphasize how under-studied the agriculturenutrition field has been, even though this seems to be changing. A recent scoping assessment of research on the agriculturenutrition nexus identified eight clear research gaps, one of which was"governance, policy processes and political economy as it relates to the development of agriculture-for-nutrition policies and programmes, the ability to implement them (and scale up) and for them to achieve their stated goals once implemented." (Turner et al. 2013). Only six of 151 studies investigated this area (one of which was LANSA). The present is not the first time there has been advocacy and action to improve nutrition through agriculture, but it has a decidedly different flavor from the past. Instead of focusing on dietary energy, protein, or micronutrients, the advocacy now is around a more holistic view of how agriculture can improve access to diverse diets, in addition to non-food factors including women's empowerment (World Bank 2014b). Throughout the last several decades, however, ownership of the nutrition issue in the agriculture sector has been consistently limited; appropriate targets, accountability mechanisms, and capacity have been factors in the limited political capital for nutrition (World Bank 2014b).

In recent years, several major initiatives have investigated the challenge of enhancing the nutrition sensitivity of agricultural policy and practice. Studies commissioned by FAO (FAO 2013; Herforth and Dufour 2013), Action Contre la Faim (du Vachat 2013), the World Bank (2014b), and the UN Standing Committee on Nutrition (Fanzo et al. 2013) have generated strikingly similar recommendations, which can all be related, in broad terms, to the three themes that structure the LANSA/LANEA case studies (as shown in Table 4).

Another desk study by Save the Children (of agricultural policies in 15 African countries), including case studies in Malawi and Ethiopia generated three sets of recommendations - for the African Union, for donors, and for high-burden countries (Bagnall-Oakeley et al. 2014). The last called for CAAD $\mathrm{P}$ agriculture investment plans to mainstream nutrition through a series of measures, with emphasis again being placed on multisectoral coordination, better integration, implementation and monitoring of actions, linked to strengthened systems of accountability (Dufour et al. 2013). Overall, broadly-speaking, our findings align with those of recent initiatives but with some important nuances and detail.

\section{Conclusions}

Findings from the six country case studies described in this paper in general coalesce around the need for action on several fronts to strengthen the nutrition sensitivity of agriculture. More and better evidence of links between agriculture and nutrition is needed, including operational research and evaluations of attempts to strengthen the nutrition sensitivity of agriculture. Both horizontal (cross-sectoral) and vertical (national to community) coherence with regard to policy and programme implementation need strengthening. Strategic, operational and technical capacities at different levels are needed to underpin and sustain positive change, backed up by adequate financing.

Revisiting the main research questions, we conclude by highlighting several specific challenges which consistently emerged from discussions in all six countries.

1. How do agricultural policymakers and other stakeholders perceive the issue of undernutrition, and its relationship to agri-food systems? Programmes and research need to be practical and well-adapted to the context. Ongoing engagement and interaction with the government is needed, so that communication is not just one-way, post-research outreach. Data availability is a major challenge. There is a pervasive data disconnect in that surveys rarely include both nutrition/health and food security/agricultural indicators, rendering it difficult to link underlying causes from nonhealth factors to nutrition outcomes. Improved data streams to link these types of indicators in national data collection, as well as quality and timeliness of data, could better inform understanding about agriculture-nutrition linkages, and also allow accountability.

2. What incentives and disincentives exist for decisions and actions to become more pro-nutrition? The focus within the agriculture sector has historically been, and often continues to be, on increasing production and productivity of cash crops as an engine of economic growth. Without clear and transparent systems of accountability for action, progress on nutrition will not happen. Accountability requires timely and appropriate information on how agriculture is affecting nutrition outcomes. The long-term, multisectoral and "invisible" nature of most forms of malnutrition represent challenges for holding policymakers and programme managers to account. Agriculture stakeholders may not take nutritional status indicators onboard, so other information may need to be collected toward other more proximal targets, such as diverse food production and consumption. In order to change "business as usual" within the agri-food system we need to understand political, institutional, and individual incentives and disincentives that underpin the status quo. Unless nutrition advocates understand the mindsets, motivations and the "language" of the sector, change will be elusive. Along with incentives to act, there is a need - through policy process/political economy-related research - to identify the trade-offs and potential synergies of any change.

3. What type of capacity and financing is required to maximize the nutrition sensitivity of the agri-food system? Training and education needs to be strengthened with regard to agriculture's linkages to nutrition. Leadership is a pivotal form of individual capacity, and is potentially 
transformational. Nutrition champions, policy entrepreneurs, and civil society activists at all levels need to be supported and encouraged.

Some of these challenges and their remedies may be more important than others, but most of them are linked synergistically. It is not possible, for example, for accountability to be strengthened without information on what is happening on the ground, which in turn requires appropriate systems of monitoring and communication, underpinned by strong systemic capacity. Information on what is happening is also tied to accountability. Priorities for action will be determined by need and context.

Acknowledgments This paper is a product of a collaboration between the Leveraging Agriculture for Nutrition in South Asia Research (LANSA) research programme consortium, the Agriculture for Nutrition and Health (A4NH) programme of the CGIAR, and the Food and Agriculture Organization of the United Nations (FAO). LANSA is funded by UK aid from the UK government. The views expressed do not necessarily reflect the UK Government's official policies. We would also like to acknowledge important contributions of the interviewers in each country: Samar Zuberi (CSSR, Pakistan), Neha Kohli (IFPRI, India), Barnali Chakraborty (BRAC, Bangladesh), Mesfin Beyero (consultant, Ethiopia), Margaret Wagah (consultant, Kenya), and Richard Semakula (consultant, Uganda). We are grateful to anonymous reviewers for insightful comments that improved the manuscript.

Conflict of interest The authors declare that they have no conflict of interest.

Open Access This article is distributed under the terms of the Creative Commons Attribution 4.0 International License (http:// creativecommons.org/licenses/by/4.0/), which permits unrestricted use, distribution, and reproduction in any medium, provided you give appropriate credit to the original author(s) and the source, provide a link to the Creative Commons license, and indicate if changes were made.

\section{References}

Bagnall-Oakeley, H., Rumsby, M., \& McNair, D. (2014). Nutrition sensitivity: How agriculture can improve child nutrition. London: Save the Children.

Balagamwala, M., \& Gazdar, H. (2013). Agriculture and nutrition in Pakistan: pathways and disconnects. Oxford IDS Bulletin, 44(3), 66-74.

Black, R. E., Victora, C. G., \& Walker, S. P. (2013). Maternal and child undernutrition and overweight in low-income and middle-income countries. The Lancet, 382, 427-451.

Cheong, D., Jansen, M., \& Peters, R. (Eds.). (2013). Shared harvests: Agriculture, trade, and employment. Geneva: UNCTAD and ILO.

$\mathrm{du}$ Vachat, E. (2013). Sowing the seeds of good nutrition. Making agricultural policies deliver better nutrition. Paris: Action Contre la Faim.

Dufour, C., Jelensperger, J., \& Uccello, E. (2013). Mainstreaming nutrition in agriculture investment plans in sub-Saharan Africa: lessons learnt from the NEPAD CAADP nutrition capacity development initiative. SCN News, 40, 61-68.

Ethiopia Central Statistical Agency and ICF International. (2012). Ethiopia demographic and health survey (DHS) 2011. Addis Ababa, Ethiopia and Calverton, Maryland, USA: Central Statistical Agency and ICF International. http://dhsprogram.com/ pubs/pdf/FR255/FR255.pdf. Accessed 22 August 2014.
Fanzo, J., Cohen, M., Sparling, T., Olds, T., \& Cassidy, M. (2013). The nutrition sensitivity of agriculture and food policies: a summary of eight country case studies. SCN News, 40, 19-25.

FAO. (1996). Rome declaration on world food security and world food summit plan of action. Rome: FAO.

FAO. (2013). State of food and agriculture: Food systems for better nutrition. Rome: FAO.

FAO (2014a). FAOSTAT country profile for Ethiopia. http://faostat.fao. org/CountryProfiles/Country_Profile/Direct.aspx?lang=en\&area= 238. Accessed December 82015

FAO (2014b). FAOSTAT country profile for Kenya. http://faostat.fao.org/ CountryProfiles/Country_Profile/Direct.aspx?lang=en\&area=114. Accessed December 82015

FAO (2014c). FAOSTAT country profile for Uganda. http://faostat.fao. org/CountryProfiles/Country_Profile/Direct.aspx?lang=en\&area= 226. Accessed December 82015

FAO/Comprehensive Africa Agriculture Development Programme (CAADP) (2013a). East and Central Africa Regional CAADP Nutrition Programme Development Workshop. Nutrition Country Paper - Ethiopia. http://www.fao.org/fileadmin/user upload/wa workshop/ECAfrica-caadp/Ethiopia_NCP_190213.pdf. Accessed August 282014

FAO/Comprehensive Africa Agriculture Development Programme (CAADP) (2013b). East and Central Africa Regional CAADP Nutrition Programme Development Workshop. Nutrition Country Paper - Uganda. http://www.fao.org/fileadmin/user_upload/wa workshop/ECAfrica-caadp/Uganda_NCP_190213.pdf. Accessed August 282014.

Gillespie, S., Haddad, L., Mannar, V., Nisbett, N., \& Menon, P. (2013). The politics of reducing malnutrition: building commitment and accelerating progress. The Lancet, 382, 552-569.

Herforth, A. \& Ahmed, S. (2015). The food environment, its effects on dietary consumption, and potential for measurement within agriculture-nutrition interventions. Food Security. (this volume)

Herforth, A., \& Dufour, C. (2013). Key recommendations for improving nutrition through agriculture: establishing a global consensus. SCN News, 40, 33-38.

Hoddinott, J., Rosegrant, M., \& Torero, M. (2012). Hunger and malnutrition: Investments to reduce hunger and undernutrition. Washington: Copenhagen Consensus, 2012.

Kadiyala, S., Harris, J., Headey, D., Yosef, S., \& Gillespie, S. (2014). Agriculture and nutrition in India: mapping evidence to pathways. Annals of the New York Academy of Sciences. doi:10.1111/nyas.12477.

Kenya Agricultural Research Institute (KARI) (2012). Policy responses to food crisis in Kenya. Washington DC: International Food Policy Research Institute. http://www.foodsecurityportal.org/kenya/foodsecurity-report-prepared-kenya-agricultural-research-institute. Accessed 6 January, 2013.

Levitt, E. J., Pelletier, D. L., \& Pell, A. N. (2009). Revisiting the UNICEF malnutrition framework to foster agriculture and health sector collaboration to reduce malnutrition: a comparison of stakeholder priorities for action in Afghanistan. Food Policy, 34, 156-165.

Levitt, E. J., Pelletier, D. L., Dufour, C., \& Pell, A. (2011). Harmonizing agriculture and health sector actions to improve household nutrition: policy experiences from Afghanistan (2002-2007). Food Security, 3(3), 363-381.

Ruel, M., \& Alderman, H. (2013). Nutrition-sensitive interventions and programmes: how can they help to accelerate progress in improving maternal and child nutrition? The Lancet, 382, 536-551.

Turner, R., Hawkes, C., Waage, J., Ferguson, E., Haseen, F., Homans, H., Hussein, J., Johnston, D., Marais, D., McNeill, G., \& Shankar, B. (2013). Agriculture for improved nutrition: the current research landscape. Food \& Nutrition Bulletin, 34(4), 369-377. 
United Nations Children's Fund (2013). Improving Child Nutrition. The achievable imperative for global progress. New York: UNICEF. http://www.unicef.org/gambia/Improving_Child Nutrition - the achievable_imperative_for_global_progress.pdf. Accessed 252014.

United Nations Children's Fund (2014). Nutritional status indicators including underweight, wasting, stunting, and overweight. http://data. unicef.org/nutrition/malnutrition\#sthash. Accessed August 252014.

United Nations Children's Fund, World Health Organization, The World Bank. (2012). UNICEF WHO-world bank joint child malnutrition estimates. New York: UNICEF.

Webb, P., \& Block, S. (2012). Support for agriculture during economic transformation: impacts on poverty and undernutrition. PNAS. doi: 10.1073/pnas.0913334108.

World Bank (2014a). Data. http://data.worldbank.org/indicator/NV.AGR. TOTL.ZS/countries. Accessed August 26, 2014.

World Bank. (2014). Learning from world bank history: Agriculture and food-based approaches to address malnutrition (Agricultural and Environmental Sciences Discussion Paper 10, World Bank Report No. 88740-GLB). Washington: World Bank.

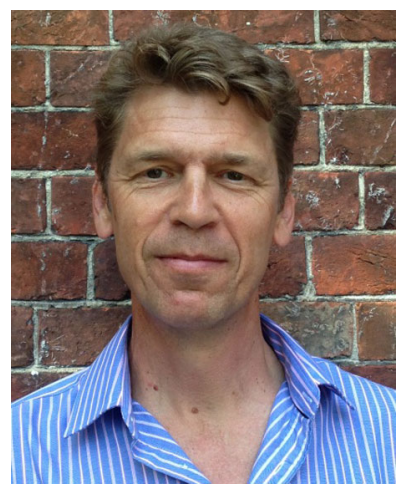

Stuart Gillespie Stuart Gillespie is a Senior Research Fellow with the International Food Policy Research Institute (IFPRI), CEO of the Transform Nutrition Research Programme Consortium, Research Director of the Leveraging Agriculture for Nutrition in South Asia (LANSA) consortium, and leader of the CGIAR Agriculture for $\mathrm{Nu}-$ trition and Health $(\mathrm{A} 4 \mathrm{NH})$ policy flagship. He has a PhD in Human Nutrition from the London School of Hygiene and Tropical Medicine (1988). Prior to joining IFPRI in 1999, he worked with UNICEF, World Bank, WFP, FAO, WHO, UNSCN, $\mathrm{ADB}$ and other agencies on nutrition policy analysis and program support. $\mathrm{He}$ has over 130 publications, including 9 books.

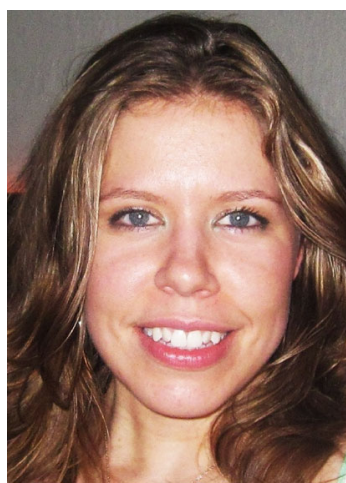

Mara van den Bold is a Research Analyst at the International Food Policy Research Institute (IFPRI), Washington, D.C. Her research interests include gender, nutrition, agriculture and agrarian reform, and political ecology. She has an MSc from the London School of Economics in Anthropology and Development Studies. Prior to joining IFPRI in 2012, she worked for several years on water, sanitation and hygiene issues with a non-governmental organization, based in London UK.

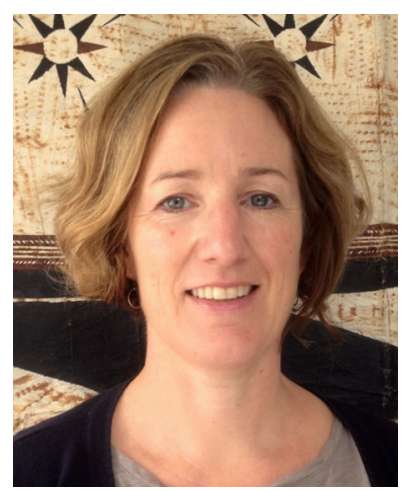

Judith Hodge Judith Hodge is an independent consultant on global food security and nutrition. She was study co-ordinator for the Leveraging Agriculture for Nutrition in East Africa (LANEA) research project. Her current role is country uptake/national communications for the Global Nutrition Report. Judith has a Masters of Science in Public Health Nutrition from the London School of Tropical Hygiene and Medicine (2013). She has worked for the International Food and Policy Research Institute (IFPRI), Welthungerhilfe, FAO and the Institute of Development Studies (IDS).

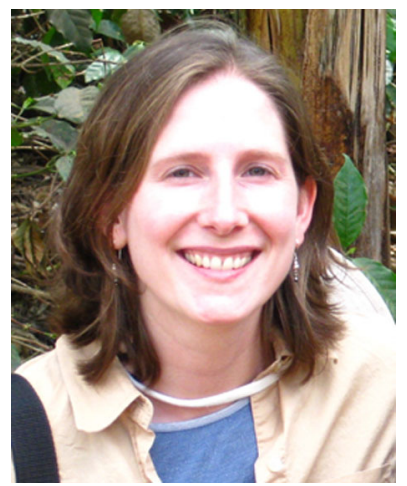

Anna Herforth Anna Herforth is a consultant specializing in the links between nutrition, agriculture and the environment. She consults for the World Bank, the UN Food and Agriculture Organization (FAO), and USAID's SPRI NG Project, among others. She has worked with universities, nonprofit organizations, and the CGIAR on food and nutrition in Africa, South Asia, and Latin America. She holds a Ph.D. from Cornell University in International Nutrition, an M.S. in Food Policy from Tufts Friedman School, and a B.S. in Plant Science from Cornell University. She is a founding member of the Agriculture-Nutrition Community of Practice. 